\title{
Olfactory alterations in patients with multiple sclerosis
}

\author{
Alterações de olfato em portadores de esclerose múltipla \\ Sergio Semeraro Jordy', Alberto Starzewski Junior², Felipe André Basso Macedo², Gabriela Reginatto Manica², \\ Charles Peter Tilbery', Eduardo Gregorin Carabetta ${ }^{1}$
}

\begin{abstract}
This cross-sectional study involves 100 multiple sclerosis (MS) and 100 non-MS patients, under the age of 60 years old, with nasal obstruction, traumatic brain injury, previous rhinoplasty or neurosurgery, and so forth. Objective: To assess olfactory function using the Connecticut test and verify correlations between olfactory alteration, disease duration and the Expanded Disability Status Scale (EDSS). Methods: One hundred MS patients and 100 healthy control patients responded to a questionnaire. Those with olfactory alteration underwent a facial CT to exclude other causes. Results: Thirty-two percent of patients showed alterations, compared with $3 \%$ in the healthy control group. Patients having EDSS above 4, showed a 5.2-times increased risk of dysfunction. Patients over 38 years of age have a 2.2-times increased risk over younger patients. Conclusions: Because MS patients are likely to experience olfactory alterations, this study is a useful tool in follow-up care, although more studies are necessary to evaluate the correlations in MS evolution.
\end{abstract}

Keywords: multiple sclerosis; smell.

\section{RESUMO}

Estudo transversal em que pacientes portadores de esclerose múltipla (EM) do ambulatório do CATEM e controles saudáveis foram submetidos a avaliação de função olfativa. Objetivo: Avaliar a função olfativa através do teste de Connecticut (CCCRC) em pacientes com EM e verificar possível correlação entre a alteração de olfato com o tempo de doença e o Expanded Disability Status Scale (EDSS). Métodos: No total, 100 pacientes com EM e 100 pacientes controles participaram do estudo. Aqueles que apresentaram alteração de olfato realizaram TC de face para excluir outras possiveis causas para a alteração olfativa. Resultados: $32 \%$ apresentaram alterações do olfato, enquanto apenas 3\% dos controles apresentaram semelhante alteração. Obtendo-se uma correlação entre o EDSS e alteração olfatória para pacientes com EDSS acima de 4. Pacientes com mais de 38 anos apresentam 2,2 vezes mais risco de ter alterações no olfato. Conclusões: Neste estudo observou-se que a alteração olfativa está presente nos pacientes portadores de EM e essa alteração pode ser uma ferramenta útil no acompanhamento desses pacientes.

Palavras-chave: esclerose múltipla; olfato.

Multiple sclerosis (MS) is an autoimmune neurological disease with a progressive nature, culminating in demyelination and axonal damage in the central nervous system. It is the most common cause of non-traumatic neurological disability in young adults.

Historically, the onset of MS is often preceded by a clinically isolated syndrome, frequently in the optic nerve, brain stem, or spinal cord. A large number of patients present with a relapsing-remitting condition (RRMS), which may be followed by a progressive decline called the secondary progressive form. A few patients do not experience relapses, having the progressive course from the onset of the condition (primary progressive form). Around $10 \%$ to $15 \%$ of RRMS patients may also remain clinically stable for many years (benign MS) ${ }^{1}$. The clinical characteristics of MS reflect the complex interaction between inflammation, demyelination and axonal damage ${ }^{2}$.

Olfactory dysfunction is often ignored by health teams as it may appear irrelevant and is rarely life-threatening, however, it usually entails psychosocial and nutritional problems, which affect the patient's quality of life. The olfactory function is essential in everyday life activities such as tasting food and beverages, alerting for fire, toxic gases and expired food. Many professionals require full olfactory function: cooks,

${ }^{1}$ Centro de Atendimento e Tratamento de Esclerose Múltipla - CATEM, Santa Casa de Misericórdia de São Paulo, São Paulo SP, Brasil;

Universidade Anhembi Morumbi, Faculdade de Medicina, São Paulo SP, Brasil.

Correspondence: Charles Peter Tilbery; CATEM, Irmandade da Santa Casa de Misericórdia de São Paulo; Rua Cesario Mota Junior, 112 / $3^{\circ}$ andar; $01221-020$ São Paulo SP, Brasil; Email: charlespt@einstein.br

Conflict of interest: There is no conflict of interest to declare.

Received 11 January 2016; Received in final form 29 May 2016; Accepted 31 May 2016. 
firefighters, beverage tasters, natural gas, chemicals and industrial substances workers ${ }^{3,4}$.

Olfactory dysfunction is often an early manifestation of other central nervous system neurodegenerative diseases such as Parkinson's disease, Alzheimer's disease, Huntington's disease $^{5}$ and Lewy body dementia, and its assessment may be useful for diagnosis ${ }^{6}$. Olfactory dysfunction in MS has also been reported in the literature ${ }^{7}$. Some studies have shown that it is related to lesions in the olfactory regions in the brain (inferior frontal and temporal lobe) ${ }^{6}$.

Studies that investigated the olfactory function in MS patients showed a hyposmia of $15 \%$ according to Hawkes and Shepard ${ }^{8}$; according to Zivadinov et al. ${ }^{9}$ it was $22 \%$, and according to Doty's study, 38.5\% compared to control groups ${ }^{10}$. The reduction of olfactory function can improve during remission periods and worsen during relapses ${ }^{6}$. The olfactory function in MS patients affects the detection threshold capacity, which is damaged in the early stage of the disease, and the ability to identify smells, which appears to be more correlated with the disease's progression ${ }^{11}$.

This study aimed to assess the olfactory function in patients diagnosed with MS using the Connecticut Chemosensory Clinical Research Center olfactory test, to determine any correlation between the olfactory alteration, the disease duration, and the Expanded Disability Status Scale (EDSS).

\section{METHOD}

\section{Population}

This was a controlled cross-sectional study conducted with $100 \mathrm{MS}$ patients (McDonald's criteria) ${ }^{12}$, treated at the Multiple Sclerosis Care and Treatment Center of the School of Medical Sciences of Santa Casa de São Paulo, between January and June 2015. All the patients were recruited during their MS follow-up visits.

The inclusion criteria were the diagnoses of MS and being monitored and treated at the Multiple Sclerosis Care and Treatment Center's clinic.

Exclusion criteria were patients over 60 years of age, complaint of nasal obstruction, nasal allergies and/or rhinorrhea, trauma, nasal surgery, or previous neurosurgery, respiratory tract infections and the use of immunosuppressives.

All the assessed patients underwent a facial CT to exclude any other explanation for the olfactory alteration ${ }^{13}$. Before the olfactory function test, we conducted a test with the Glatzel mirror as an aid to the diagnosis of mechanical nasal obstruction ${ }^{14}$. Besides that, we assessed a control group of 100 non-MS patients, using the same exclusion criteria.

\section{Olfactory test}

After collecting data about their disease, and about the presence or absence of an olfactory complaint, the patients took the Connecticut Chemosensory Clinical Research Center olfactory test ${ }^{15}$. Only patients who had regular olfactory function (normosmia) underwent the screening ${ }^{16}$. Those who had olfactory alterations were thoroughly tested.

The Connecticut test is divided into two parts: the first assesses the smell threshold, and the second assesses the identification of smells. In both stages, each nasal cavity is assessed separately during the presentation of smells, closing them one at a time by digital compression, as it is possible to present with unilateral hyposmia/anosmia. During the test, the patient remained blindfolded ${ }^{15}$.

The threshold test uses different concentrations and dilutions of 1-butanol in 11 separate glass flasks, numbered from " 0 to 10 ", in descending order of concentration. The flask "0" corresponds to 1-butanol without dilution, at a concentration of $4 \%$. The other dilutions were in the ratio 1:3. The blindfolded patient was offered the flask of the lowest concentration ( $\#$ \# 10) and a flask with water, to identify which had the strongest smell. If the answer was wrong, the patient took the next highest concentration flask ( $n$ \# 9), and so on until they were successful. After the first correct response, the same flask was again presented to the patient, as the test is completed only when the patient responded to it correctly four times in a row, thus confirming their smell threshold, represented by the flask number ${ }^{15}$.

In the smell identification phase, seven plastic flasks containing different substances (talc, chocolate, coffee, cinnamon, naphthalene, ethyl alcohol and tobacco) are randomly presented to the patient. The patient had to name the substance after smelling it. Responses like "no smell" or "I don't know" were considered. If the response was wrong, the same substance was presented for the second time, but if there was a correct response, the previous mistake was ignored. The test score was the number of items correctly identified in the first or the second endeavor ${ }^{15}$.

The patient was finally presented with a flask containing ammonium chloride, to evaluate trigeminal perception. This was important to detect possible simulators, as the trigeminal is generally preserved in the impairment of the olfactory pathway. The total score for each cavity test was expressed by the arithmetic mean of the scores obtained in the smell threshold and smell identification.

\section{Statistical analysis}

Analysis of the results was with the statistical program SPSS version 20. The variables were expressed as mean and standard deviation for continuous variables, and recorded as a percentage (categorical variables). All tests were two-caudate. Normality tests were used based on the method of Kolmogorov-Smirnov and Shapiro-Wilk. Categorical variables were analyzed by the chi-squared method and we used the Fisher's exact test correction whenever it was necessary. Continuous variables were assessed by 
the Student's T test. To analyze olfactory alterations and continuous variables, we used linear regression.

\section{RESULTS}

One hundred MS patients were assessed, 72 women and 28 men, with an EDSS mean of 2, and an average time after diagnosis of 93 months. Olfactory alterations were observed in $32 \%$ of the MS patients, while in the control group only $3 \%$ had olfactory alteration. Tables 1 and 2 shows each group's characteristics.

The boxplot shows a cutoff of 4 for EDSS (Figure 1), which approximately coincides with the EDSS mean in patients with olfactory alteration. Therefore, if a patient has an EDSS above 4, they have (odds ratio) 5.2 times the risk of having an olfactory alteration, when compared to a patient with a lower EDSS ( $p=0.001$ ), range of confidence (95\%): 1.8-15.1.

With a sensitivity of $97 \%$ and specificity of $88 \%$, this study showed that when the EDSS value is smaller than 0.5, the patient is unlikely to show olfactory alteration.

We also observed that if an MS patient is older than 38 years, the risk of having an altered test is 2.2 times greater than a younger person $(p=0.01)$.
We also observed that MS patients without olfactory alteration were within 80.5 months after diagnosis, against 119 months duration after diagnosis in the patients who had olfactory alteration, showing a correlation between olfactory alteration and time since diagnosis $(\mathrm{p}=0.031)$.

\section{DISCUSSION}

The frequency of olfactory alteration in MS patients was $32 \%$, which is consistent with other findings in the literature, for example, the studies of Hawkes (15\%), Zivadinov $(22 \%)$ and Doty $(32.5 \%)^{8,9,10}$. The sense of smell is very important to the safety and quality of life. People with olfactory alterations have a significant reduction in food intake because of decreased pleasure, thus becoming even more susceptible to injuries ${ }^{3,4}$.

When analyzing the results, a patient with EDSS above 4 had 5.2 times the increased risk of olfactory alteration, which is consistent with other studies. Caminiti et al. ${ }^{7}$ and Silva et al. ${ }^{6}$ showed that olfactory dysfunction was correlated with higher EDSS scores, and a longer duration of disease, corroborating previous studies in which the olfactory dysfunction correlates directly to the level of disability ${ }^{8,9,11,17}$.

Table 1. Characteristics of the study population $(n=200)$.

\begin{tabular}{|c|c|c|c|c|c|c|}
\hline \multirow{2}{*}{ Variable } & \multicolumn{3}{|c|}{ MS patients [n (\%)] } & \multicolumn{3}{|c|}{ Health controls [n (\%)] } \\
\hline & Female & Male & Total & Female & Male & Total \\
\hline$N(\%)$ & $72(72)$ & $28(28)$ & $100(100)$ & $55(55)$ & $45(45)$ & $100(100)$ \\
\hline Age & 39.8 & 35.9 & 38.7 & 30.52 & 30.54 & 30.47 \\
\hline EDSS & 2 & 2 & 2 & - & - & - \\
\hline Olfaction affetions [n (\%)] & $22(68.75)$ & $10(31.25)$ & $32(100)$ & $1(33.3)$ & $2(66.6)$ & $3(100)$ \\
\hline Time of diagnosis & 91 & 76 & 93 & - & - & - \\
\hline
\end{tabular}

MS: multiple sclerosis; EDSS: Expanded disability status scale.

Table 2. Treatment and medications $(n=200)$.

\begin{tabular}{lccc}
\hline \multirow{2}{*}{ Variable } & \multicolumn{3}{c}{ MS patients } \\
\cline { 2 - 4 } & $\begin{array}{c}\text { Female } \\
{[\mathrm{n}(\%)]}\end{array}$ & $\begin{array}{c}\text { Male } \\
{[\mathrm{n}(\%)]}\end{array}$ & Total (n) \\
\hline None & $35(48,7)$ & $9(32,1)$ & 44 \\
\hline Avonex & $9(12,5)$ & $6(21,4)$ & 15 \\
\hline Rebif 22 & $1(1,4)$ & 0 & 1 \\
\hline Rebif 44 & 0 & $3(10.7)$ & 3 \\
Gylenia & $12(16,7)$ & $1(3,6)$ & 13 \\
\hline Tysabri & $6(8,3)$ & $5(17,9)$ & 11 \\
\hline Betaferon & $1(1,4)$ & $2(7,1)$ & 3 \\
Copaxone & $6(8,3)$ & $2(7,1)$ & 8 \\
\hline Tecfidera & $2(2,8)$ & 0 & 2 \\
\hline
\end{tabular}

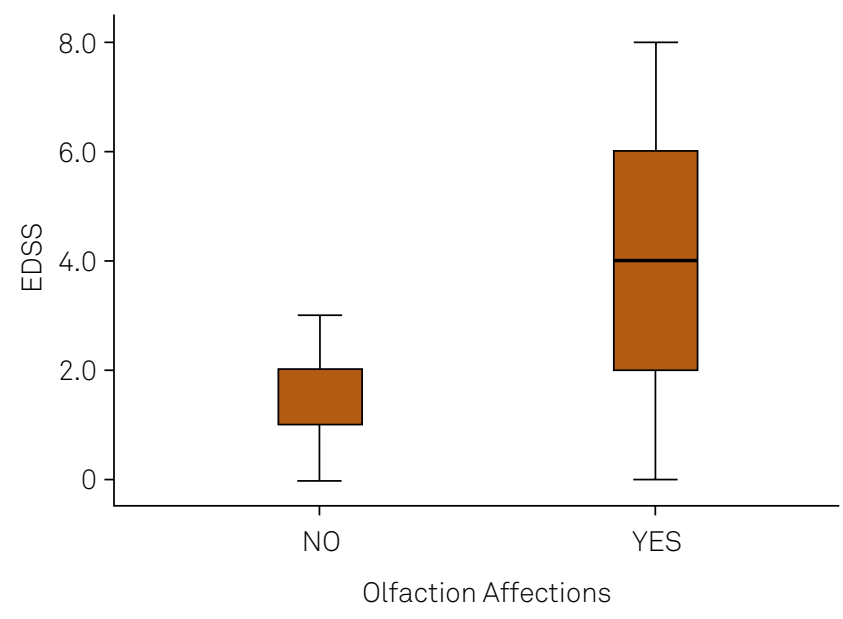

Figure 1. Boxplot from cutoff EDSS in olfactory alterations. 
Considering the relationship between the time of diagnosis and olfactory alteration, this study showed that patients with an abnormal test had a longer duration since diagnosis ( $p=0.031$ ), an average of 119 months, and that the older the patient, the greater the risk of olfactory alteration, as described by Silva et $\mathrm{al}^{6}$. The correlation of olfactory alteration and age demonstrated that MS patients over 38 years old are 2.2 times $(p=0.01)$ more likely to have olfactory alteration.

In the study by Silva et al. ${ }^{6}$, it was observed that the EDSS mean in all the patients studied was $2.92 \pm 2.25$ with a mean age of $41.91 \pm 11.28$ years, while in patients with olfactory alterations the EDSS mean was around $5.26 \pm 2.22$ $(p<0.001)$, with a mean age of $51,47 \pm 10.03$ years. In our study, the studied population's EDSS mean was 2, but it was 4 in patients with alteration, with an age of 38 years. This demonstrates similarity between our population and Silva et al. ${ }^{6}$.

In conclusion, through the data obtained in this study we observed that MS patients are likely to experience olfactory alteration, so its assessment may be a useful tool to the follow-up care of these patients, although more studies are necessary to evaluate correlations in MS evolution.

\section{References}

1. Gold R, Wolinsky JS. Pathophysiology of multiple sclerosis and the place of teriflunomide. Acta Neurol Scand. 2011;124(2):75-84. doi: 10.1111/j.1600-0404.2010.01444.X

2. Lassmann $\mathrm{H}$. Axonal and neuronal pathology in multiple sclerosis: what have we learnt from animal models. Exp Neurol. 2010;225(1):2-8. doi:10.1016/j.expneurol.2009.10.009

3. Starzewski Junior A, Guilherme A, Augusto LBS. Distúrbios do olfato. Rev Bras Med. 2008;3:78-84.

4. Deems DA, Doty RL, Settle RG, Moore-Gillon V, Shaman P, Mester AF et al. Smell and taste disorders: a study of 750 patients from the University of Pennsylvania Smell and Taste Center. Arch Otolaryngol Head Neck Surg. 1991;117(5):519-28. doi:10.1001/archotol.1991.01870170065015

5. Barresi M, Ciurleo R, Giacoppo S, Foti Cuzzola V, Celi D, Bramanti P et al. Evaluation of olfactory dysfunction in neurodegenerative diseases. J Neurol Sci. 2012;323(1-2):16-24. doi:10.1016/j.jns.2012.08.028

6. Silva AM, Santos E, Moreira I, Bettencourt A, Coutinho E, Gonçalves A et al. Olfactory dysfunction in multiple sclerosis: association with secondary progression. Mult Scler. 2011;18(5):616-21. doi:10.1177/1352458511427156

7. Caminiti F, De Salvo S, De Cola MC, Russo M, Bramanti P, Marino S et al. Detection of olfactory dysfunction using olfactory event related potentials in young patients with multiple sclerosis. PLoS One. 2014;9(7):e103151. doi:10.1371/journal.pone.0103151

8. Hawkes $\mathrm{CH}$, Shephard BC. Olfactory evoked responses and identification tests in neurological disease. Ann NYAcad Sci. 1998;855 1 OLFACTION AND:608-15. doi:10.1111/j.1749-6632.1998.tb10631.x

9. Zivadinov R, Zorzon M, Monti Bragadin L, Pagliaro G, Cazzato G. Olfactory loss in multiple sclerosis. J Neurol Sci, 1999;168(2):127-30. doi:10.1016/S0022-510X(99)00189-6
10. Doty RL, Li C, Mannon LJ, Yousem DM. Olfactory dysfunction in multiple sclerosis. Relation to plaque load in inferior frontal and temporal lobes. Ann N Y Acad Sci. 1998;855 1 OLFACTION AND:781-6. doi:10.1111/j.1749-6632.1998.tb10658.x

11. Luterotti A, Vedovello M, Reindl M, Ehling R, DiPauli F, Kuenz B et al. Olfactory threshold is impaired in early, active multiple sclerosis. Mult Scler. 2011;17(8):964-9. doi:10.1177/1352458511399798

12. Polman $\mathrm{CH}$, Reingold SC, Banwell B, Clanet M, Cohen JA, Filippi $M$ et al. Diagnostic criteria for multiple sclerosis: 2010 revisions to the McDonald criteria. Ann Neurol. 2011;69(2):292-302. doi:10.1002/ana.22366

13. Palheta Neto FX, Targino MN, Peixoto VS, Alcântara FB, Jesus CC, Araújo DC et al. Anormalidades sensoriais: olfato e paladar. Arq Int Otorrinolaringol. 2011;15(3):350-8 . doi:10.1590/S1809-48722011000300014

14. Altmann EBC, Khoury RBF, Ramos ALNF. Avaliação fonoaudiológica. In: Altmann EBC. Fissuras labiopalatinas. 4 a ed. Carapicuiba: Pró-Fono; 1997. p. 325-66.

15. Cain WS, Gent JF, Goodspeed RB, Leonard G. Evaluation of olfactory dysfunction in the Connecticut Chemosensory Clinical Research Center. Laryngoscope. 1988;98(1):83-8. doi:10.1288/00005537-198801000-00017

16. Toledano A, González E, Rodríguez G, Galindo AN. Desarrollo de un test de screening olfatorio a partir del test de Connecticut (CCCRC). Acta Otorrinolaringol Esp. 2005;56(3):116-21. doi:10.1016/S0001-6519(05)78585-X

17. Zorzon M, Ukmar M, Bragadin LM, Zanier F, Antonello RM, Cazzato $\mathrm{G}$ et al. Olfactory dysfunction and extent of white matter abnormalities in multiple sclerosis: a clinical and MR study. Mult Scler. 2000;6(6):386-90. doi:10.1177/135245850000600605 